\title{
Hedging Tactic of CSI300 Stock Index Futures Based on Non-Symmetric Fluctuation GARCH Model
}

\author{
Jun Jin \\ The Institute of Mathematics and Statistics \\ East China Normal University \\ Shanghai, China \\ 10153700108@ecnu.cn
}

\author{
Zhaolin Jin \\ The Institute of Economics \\ East China Normal University \\ Shanghai, China \\ 10153700145@ecnu.cn
}

\begin{abstract}
This study is based on the data and improves the theoretical model of GARCH, applying EGARCH model in the A-stock market. Meanwhile, an analysis on the lack of consideration on the A-share market's nonlinear asymmetry is completed. We make a change on the error of regression equation, which is generally considered as the normal distribution. Through optimization, we can build an asymmetric model based on the empirical data to provide a better hedging model and hedging recommendations.
\end{abstract}

Keywords- Hedging; Stock Index Futures; EGARCH Model; Asymmetric Distribution; Parameter Estimation

\section{INTRODUCTION}

Our project will take advantage of existing model, and empirically explores the historical data, so as to put forward a better hedge tactic and operation method based on the A-share market characteristics. First of all, an investigation of Nonsymmetric character is vital. We use "News Impact Curve" to measure this feature. Then, EGARCH model is used to conduct the regression. Finally, for the convenience of hedging customers, we need a specific discussion that hedging in difference purpose-avoiding risk or making effectiveness maximum.

\section{PREPROCESS \& MODELING}

\section{A. Data Resource}

Get the value of CSI 300 index including all the closing prices and fluctuation ratio (the unit is \%) from January 4, 2012 to October 25, 2016 (the beginning date of our project) on 'http://quotes.money.163.com/trade/lsjysj_zhishu_399300.html' (A magisterial financial website). Input all the data into MATLAB and take log of them. Since the amount of data is huge, we just list the data from October 25, 2016 to October 17, 2016 here for an exemplar.
TABLE I. DATA EXAMPLAR

\begin{tabular}{|c|c|c|c|c|}
\hline $\begin{array}{c}\text { Table } \\
\text { Head }\end{array}$ & Date & Closing Price & Change Rate & Log-return \\
\hline 1. & 2016.10 .25 & 3367.454 & -0.0037 & -0.00003700 \\
\hline 2. & 2016.10 .24 & 3367.577 & 1.1971 & 0.01189991 \\
\hline 3. & 2016.10 .21 & 3327.740 & 0.2753 & 0.00274992 \\
\hline 4. & 2016.10 .20 & 3318.604 & 0.0713 & 0.00071275 \\
\hline 5. & 2016.10 .19 & 3316.240 & -0.1533 & -0.00153417 \\
\hline
\end{tabular}

\section{B. EGARCH Model}

Why do we build an exponential GARCH model instead of other models from GARCH model family here?

EGARCH(p,q) model (Exponential Generalized Autoregressive Conditional Heteroscedasticity model) can reveal the asymmetrical reaction of conditional variance to the positive and negative information. The natural logarithm of conditional variance means that the conditional variance ht is positive. If $\varphi \mathrm{k}$ is not equal to 0 in the equation, the effect of information is asymmetrical [1].

When $\varphi \mathrm{k}$ is positive, the effect of positive information is bigger than that of negative one, which always exists when the market is confident and temporary fall of stock prices cannot shatter market's confidence; to the contrary, when $\varphi \mathrm{k}$ is negative, the effect of negative information is bigger than that of positive one, which means the market is less well-informed, unconfident and unstable.

On the basis of the EGARCH (p, q) model, we can build a regression equation:

$$
\left\{\begin{array}{l}
S_{t}=\mu_{1}+\sum_{i=1}^{R} r_{i} S_{t-i}+\sum_{i=1}^{M} \varphi_{i} \varepsilon_{t-i}+\varepsilon_{t} \\
\varepsilon_{t}=u_{t} \sqrt{h_{t}} \\
\ln \left(h_{t}\right)=\omega+\sum_{i=1}^{p}\left[\gamma_{i}\left|\frac{\varepsilon_{t-i}}{\sqrt{h_{t-i}}}\right|+\alpha_{i} \frac{\varepsilon_{t-i}}{\sqrt{h_{t-i}}}\right]+\sum_{i=1}^{q} \beta_{i} \ln \left(h_{t-i}\right)
\end{array}\right.
$$


The unit of time (t) is "day" and ut is the standard normal distribution. The first equation is a conditional mean equation, and the second a conditional error equation. The third one is a conditional variance equation.

\section{News Impact Curve}

Inventor: Engle and NG (1993)

Function: make the asymmetrical effect of information more intuitive (asymmetrical or symmetrical)

Definition: in the conditional variance equation of formula (1), we suppose that the residual error $\varepsilon t$ is normal distribution, set the equation: [2]

$$
\mathrm{f}\left(\frac{\varepsilon_{t-1}}{h_{t-1}}\right)=\alpha \frac{\varepsilon_{t-1}}{h_{t-1}}+\gamma\left|\frac{\varepsilon_{t-1}}{h_{t-1}}\right|
$$

Let's suppose that $z_{t}=\frac{\varepsilon_{t}}{h_{t}}$, then we can get:

$$
\mathrm{f}\left(z_{t-1}\right)=\alpha z_{t-1}+\gamma\left|z_{t-1}\right|
$$

In the equation, $\mathrm{f}(\cdot)$ is the "information curve" namely the curve to depict the volatility after the impact.

\section{FITTING \& CURVE MAKING}

Before we begin to fit the data, we must claim that all of following computer operation is completed with $\mathrm{R}$ as computer language.

\section{A. Data Fitting}

Next we choose CSI 300 index futures as an example to do the data fitting, after which compare the fitting results in the different intervals.

Since there is a complete package of GARCH family models in the $\mathrm{R}$ Language, we choose it as our solving platform. We use conditional mean equation $\operatorname{ARMA}(1,1)$ and conditional variance equation EGARCH $(1,1)$ to fit the CSI 300 index.

Import our data into the Rstudio. Then, we use "gosolnp" solver to deal and then plot the information curve with the data of 365 trading days (the step length is “day”).

\section{B. Result display}

- Optimal parameters

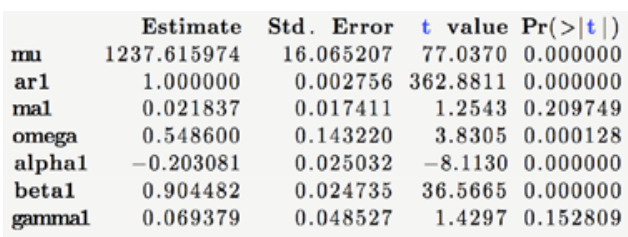

- Information criteria

$\begin{array}{ll}\text { Akaike } & 8.5399 \\ \text { Bayes } & 8.6147 \\ \text { Shibata } & 8.5392 \\ \text { Hannan-Quinn } & 8.5697\end{array}$

- Weighted Ljung-Box test

$\begin{array}{lrr} & \text { statistic } & \text { p-value } \\ \operatorname{Lag}[1] & 0.002161 & 0.9629 \\ \operatorname{Lag}[2 *(p+q)+(p+q)-1][5] & 1.837748 & 0.9811 \\ \operatorname{Lag}[4 *(p+q)+(p+q)-1][9] & 3.416801 & 0.8179 \\ \text { d. o. } \mathbf{f}=2 & & \end{array}$

\section{Curve making}

We substitute the estimated value of parameter above (alpha $=-0.203081,0.069379)$ into the news impact curve Equation (3) and get the image as follows:

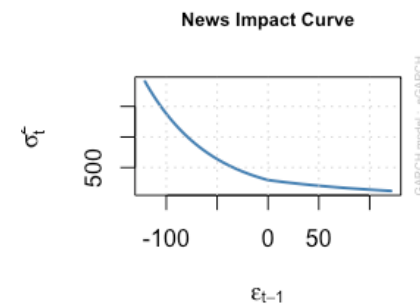

Fig. 1. News impact curve of 365 trading days

Similarly, we can get the fitting result of last 730 trading days only by changing the internal selected interval of data matrix. We can get alpha=-0.130489, gamma=0.109542 Similarly, we can plot the image as follows:

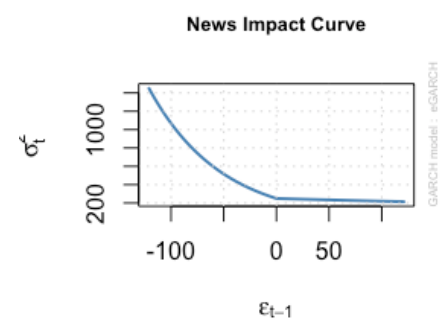

Fig. 2. News impact curve of 730 trading days

In like manner, we can get the fitting result of the last 1095 trading days:

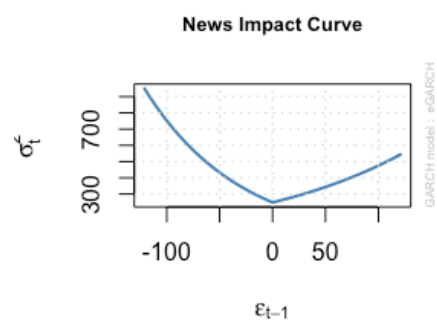

Fig. 3. News impact curve of 730 trading days

Obviously, we find that the positive expectations (or the symmetry) of CSI 300 index is worse and worse affected by the bleak market, which means the equivalent positive information brings about less impact while the equivalent negative one brings about more impact. Nevertheless, this cannot make us abandon the hedging products, since the market may wax and wane. 
Still, we realize that compared with the stock index overseas (DAX for example, we use the similar method here, there is no need to elaborate), CSI 300 index has the typical asymmetry of market on account of the investor's risk repugnance. Therefore, hedging products in consideration of asymmetry are in line with trend.

\section{PRINCIPLE OF PREDICTION}

\section{A. Stock index prediction}

As is known to all, GARCH family models have the capacity of prediction naturally [3]. Due to the fact that we use conditional mean equation ARCH $(1,1)$ and conditional variance model EGARCH $(1,1)$, we substitute the stock index and variance of last interval into the regression model:

$$
\left\{\begin{array}{l}
S_{t}=\mu_{1}+r_{1} S_{t-1}+\varphi_{1} \varepsilon_{t-1}+\varepsilon_{t} \\
\varepsilon_{t}=u_{t} \sqrt{h_{t}} \\
\ln \left(h_{t}\right)=\omega+\gamma_{1}\left|\frac{\varepsilon_{t-1}}{\sqrt{h_{t-1}}}\right|+\alpha_{1} \frac{\varepsilon_{t-1}}{\sqrt{h_{t-1}}}+\beta_{1} \ln \left(h_{t-1}\right)
\end{array}\right.
$$

\section{B. Volatility prediction}

To measure the volatility, we can either substitute the volatility of last interval into the equation as what we do in the stock index prediction, or iterate over high frequency log-return without observing stock index data [4].

Data processing:

$$
\left\{\begin{array}{l}
R_{t}=\sum_{k=1}^{K} R_{k, t} \\
\operatorname{Var}\left(R_{t} \mid F_{t-1}\right)=\sum_{k=1}^{K} \operatorname{Var}\left(R_{k, t} \mid F_{t-1}\right)+2 \sum_{k<j} \operatorname{Cov}\left[\left(R_{k, t}, R_{j, t} \mid F_{t-1}\right)\right] \\
\operatorname{Var}\left(R_{t} \mid F_{t-1}\right)=n \operatorname{Var}\left(R_{1, t}\right) \\
\widehat{\sigma}_{t}=\frac{n}{n-1} \sum_{k=1}^{K}\left(R_{k, t}-R_{t}\right)^{2}=\sum_{k=1}^{K} R_{k, t}^{2}
\end{array}\right.
$$

\section{Hedging STRATEgy}

Futures hedging is of multiple uses. For example, if we purchase any stock included in the CSI 300 index and want to hedge the systematic risk ( $\beta$ risk), we can do a reversing trade of CSI 300 index futures. The only problem here is the optimal hedge ratio: using how many futures contracts to hedge a stock.

We will give different solutions for different investors. When hedging, the most important factor is the hedge ratio, which means using how many futures to hedge a spot. The hedge ratio can show the effect of price changes in relevant assets to the price of futures.
As for profit, we can get: [5]

$$
\left\{\begin{array}{l}
R_{t+1}=\Delta S_{t}+1-\gamma_{t} \Delta F_{t}+1 \\
\Delta S_{t+1}=S_{t+1}-S_{t} \\
\Delta F_{t+1}=F_{t+1}-F_{t} \\
\sigma_{S, t+1}^{2}=\operatorname{Var}_{t+1}\left(S_{t+1} \mid S_{t}, \sigma_{S, t}^{2}\right) \\
\sigma_{F, t+1}^{2}=\operatorname{Var}_{t+1}\left(F_{t+1} \mid F_{t}, \sigma_{F, t}^{2}\right) \\
\sigma_{S, F, t+1}^{2}=\operatorname{Cov}_{t+1}\left(S_{t+1}, F_{t+1}\right) \\
\sigma_{t+1}^{2}=\operatorname{Var}\left(R_{t+1}\right)=\sigma_{S, t+1}^{2}+\gamma_{t}^{2} \sigma_{F, t+1}^{2}-2 \sigma_{S, F, t+1}^{2}
\end{array}\right.
$$

In the formula, $\mathrm{R}$ (change by times) is the total revenue, $\mathrm{S}$ and $\mathrm{F}$ (change by times) are the price of spot and price of futures respectively. Gamma is the optimal hedging ratio in the current interval.

In view of above-mentioned formulas, we can tell two kinds of investors: investors aimed at risk minimization and investors aimed at utility maximization. The difference between them is that when the former investors are confident in the market, they may exposure part of their hedging risk due to their different risk aversion coefficient. However, the latter investors will not do that.

\section{A. Risk minimization hedging}

When the investors are aimed at risk minimization, we can get:

$$
\begin{gathered}
\frac{d}{d_{y_{t}}}\left(\sigma_{t+1}^{2}\right)=0 \\
\Leftrightarrow \gamma_{t}^{*}=\frac{\operatorname{Cov}_{t+1}\left(s_{t+1}, F_{t+1}\right)}{\operatorname{Var}\left(F_{t+1}\right)}
\end{gathered}
$$

We can see from here that, by iterating the data we can easily get the distribution of stock index and stocks in the interval $t+1$, and then we can obtain the optimal hedge ratio of risk minimization hedging. Next, we will choose CNPC (601857) (a heavyweight stock of CSI 300) and CSI 300 index futures as our example to operate.

Specific code is omitted.

At last, we can get Gamma, namely the optimal hedge ratio of risk minimization hedging. In the example, Gamma=2.766048e-10. This number is seemingly minuscule; however, one portion of stock index future is expensive which makes the hedging considerably important.

\section{B. Utility maximization hedging}

- Measure the risk aversion coefficient

For any investor, if the utility function is known, the risk aversion coefficient can be calculated.

Set $\tilde{g}$ as a Fair Game pay, that $\mathrm{E}(\tilde{\mathrm{g}})=0$.

$\mathrm{U}(\bullet)$ is Investor's utility function.

From the above hypothesis, we can get the method of describing risk aversion:

$$
\begin{gathered}
E[u(w+\tilde{g})]=u(w-\pi) \\
\text { Taylor } \Rightarrow \pi=\frac{1}{2}\left[-\frac{u^{\prime \prime(w)}}{u^{\prime(w)}}\right] \operatorname{Var}[\tilde{g}]
\end{gathered}
$$


In the formula, $\pi$ is aversion measure that is the compensatory wealth for uncertainty. Thus, the risk aversion coefficient is:

- Hedging strategy

$$
\begin{aligned}
& A(w)=-\frac{u^{\prime \prime}(w)}{u^{\prime}(w)} \text { (Arrow) } \\
& R(w)=w A(w) \text { (Relative) }
\end{aligned}
$$

When the investors are aimed at utility maximization, we can get:

$$
\begin{gathered}
E_{t+1} U\left(R_{t+1}\right)=E_{t+1}\left(R_{t+1}\right)-k \operatorname{Var}_{t+1}\left(R_{t+1}\right) \\
\frac{d}{d_{t}}\left(E_{t+1} U\left(R_{t+1}\right)\right)=0 \\
\Leftrightarrow \gamma_{t}^{* *}=\frac{\operatorname{Cov}_{t+1}\left(S_{t+1}, F_{t+1}\right)}{\operatorname{Var}_{t+1}\left(F_{t+1}\right)}-\frac{E_{t+1}\left(\Delta F_{t+1}\right)}{2 k \operatorname{Var}_{t+1}\left(\Delta F_{t+1}\right)} \\
\Leftrightarrow \gamma_{t}^{* *}=\gamma_{t}^{*}-\frac{E_{t+1}\left(F_{t+1}\right)-F_{t}}{2 k \operatorname{Var}_{t+1}\left(F_{t+1}\right)}
\end{gathered}
$$

The program is similar to that of investors aimed at risk minimization, except for some short additional codes.

The Gamma we get is the optimal hedge ratio of utility maximization hedging. In the example, Gamma=2.766079e- 10 .

\section{HEDGING STRATEGY}

It is noteworthy that the log-return of stocks are volatility clustering due to the formula $\mathrm{Rt}=\ln (\mathrm{St})-\ln (\mathrm{St}-1)$. In other words, before every big fluctuation, there will be abnormal data, for example, a very low return. Based on this, we can set up an early warning system to stop the hedge ahead and avoid the uncertain loss when there is abnormal data. Next we will build the early warning system.

According to the reasons above, we might as well draw a curve of VaR:

$$
\text { Var }=\sigma \mathrm{p}+\text { fitValue }_{\text {EGARCH }}
$$

In the formula, $\sigma$ is the variance calculated by processing the historical data using EGARCH model, and p is the quantile of the standardized normal distribution, which can be adjusted due to the accuracy needed. We might as well suppose the significance level at one percent, then the fitValue EGARCH $_{\text {is }}$ is the fitting result of EGARCH model. We will measure the design here (choosing a past time as the beginning time).

Results display:

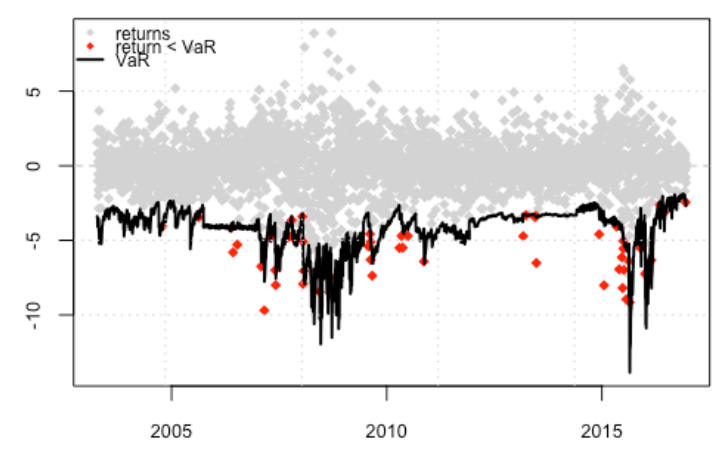

Fig. 4. The early warning system detects some abnormal data

Thus, an appearance of red dot is always followed by a big fluctuation of return. From the image, it is obvious that the early warning system is significant.

\section{CONCLUSION}

Applying forensic analysis, we confirmed that the CSI300 index has symmetrical attribute which could not be ignored when fund managers want to form a portfolio. Besides, the rudimentary probabilistic method and the fundamental VAR test is an efficacious method to establish and manage portfolio.

\section{REFERENCES}

[1] .Dai J, Zhu X L, Management S O. Hedging Effectiveness of the Hushen 300 Stock Index Futures Contracts[J]. Chinese Journal of Management Science, 2014.

[2] .Yuan K A. GARCH Model of the Dissymmetrical Shanghai Stock Markets[J]. Science Technology \& Engi- neering, 2009.

[3] Hsu C C, Tseng C P, Wang Y H. Dynamic hedging with futures: A copula-based GARCH model[J]. Journal of Futures Markets, 2008, 28(11):1095-1116.

[4] Yuan K A. GARCH Model of the Dissymmetrical Shanghai Stock Markets[J]. Science Technology \& Engi- neering, 2009.

[5] .Nguyen M K, Lan A T, Thi T H V. Market efficiency of China and Thailand commodity futures exchanges.[J]. 2007. 